University of Nebraska - Lincoln

DigitalCommons@University of Nebraska - Lincoln

USDA National Wildlife Research Center - Staff Publications
U.S. Department of Agriculture: Animal and Plant Health Inspection Service

May 2001

\title{
Monitoring changes in feral swine abundance and spatial distribution
}

Richard M. Engeman

USDA-APHIS-Wildlife Services, s_r100@yahoo.com

Bernice Constantine

USDA/APHIS/WS

Mark Nelson

Jonathan Dickinson State Park

John Woolard

USDA/APHIS/WS

Jean Bourassa

National Wildlife Research Center

Follow this and additional works at: https://digitalcommons.unl.edu/icwdm_usdanwrc

Part of the Environmental Sciences Commons

Engeman, Richard M.; Constantine, Bernice; Nelson, Mark; Woolard, John; and Bourassa, Jean, "Monitoring changes in feral swine abundance and spatial distribution" (2001). USDA National Wildlife Research Center - Staff Publications. 168.

https://digitalcommons.unl.edu/icwdm_usdanwrc/168

This Article is brought to you for free and open access by the U.S. Department of Agriculture: Animal and Plant Health Inspection Service at DigitalCommons@University of Nebraska - Lincoln. It has been accepted for inclusion in USDA National Wildlife Research Center - Staff Publications by an authorized administrator of DigitalCommons@University of Nebraska - Lincoln. 


\title{
Monitoring changes in feral swine abundance and spatial distribution
}

\author{
RICHARD M. ENGEMAN ${ }^{1 *}$, BERNICE CONSTANTIN ${ }^{2}$, MARK NELSON $^{3}$, JOHN WOOLARD $^{2}$ \\ AND JEAN BOURASSA ${ }^{1}$ \\ ${ }^{1}$ National Wildlife Research Center, 4101 LaPorte Ave, Fort Collins, CO 80521-2154, USA, ${ }^{2}$ USDA/APHIS/WS, 2820 East University \\ Avenue, Gainesville, FL 32641, USA and ${ }^{3}$ Jonathan Dickinson State Park, 16450 SE Federal Highmay, Hobe Sound, FL 33455, USA
}

Date submitted: 19 January 2001 Date accepted: 26 May 2001

\section{Summary}

Swine (Sus scrofa) have been introduced in many places throughout the world, and in many places they adversely affect the environment, economically impact agriculture, and/or harbour diseases transmittable to domestic livestock or humans. An easily applied method to assess their abundance is an important need for their management. To monitor efficacy of a swine control programme in Florida, data from passive tracking plots provide an index of feral swine abundance. The same track data coupled with plot locations to numerically describe the spatial pattern of swine activity gave an index of pervasiveness, and a simple rate of interception of damage sites to index damage was used. The assessments were conducted in January, May, and August 2000 in Jonathan Dickinson State Park, Florida, USA. Between the first two assessments a swine control programme removed 25 feral swine from the $8.3 \mathrm{~km}^{2}$ study area, after which the value of the passive tracking index was reduced by $81 \%$ and the fresh damage index by $89 \%$, while the index of spatial pattern (pervasiveness index) showed only a small localized concentration after control. In the three months following the second assessment, Park personnel removed three additional swine from the study area, and a follow-up assessment indicated slightly less swine activity than immediately after the post-control assessment, however the index of pervasiveness showed a similar spatial pattern of activity as the initial assessment, possibly indicating re-invasive pressure. The passive tracking plots proved to be an uncomplicated, easily applied means to gather data for assessing and comparing swine abundance and distribution.

Keymords: alien species, exotic species, feral hogs, feral pigs, Florida, index of pervasiveness, invasive species, passive tracking index, population index

\section{Introduction}

Feral swine (Sus scrofa) can be a particularly destructive exotic species in the places where they have been introduced

\footnotetext{
* Correspondence: Dr Richard Engeman Tel: +1 9702666091 Fax: +19702666089 e-mail: richard.m.engeman@aphis.usda.gov
}

(US Department of Agriculture 1999). Swine were first introduced to North America in Florida by DeSoto in 1539 (Towne \& Wentworth 1950) and, with additional introductions, the range of feral swine in the USA continues to expand (Gipson et al. 1997). The species possesses the highest reproductive potential of any North American large mammal (Wood \& Barrett 1979; Hellgren 1999), and currently inhabits many areas in such large numbers that it adversely impacts the environment and agriculture. Feral swine impose a variety of negative environmental impacts through habitat degradation, predation on native species, and competition with native species (Choquenot et al. 1996; Taft 1999). The species also has an economic impact on agriculture through direct losses in production of crops and livestock, control costs, and the resulting loss of alternative investment opportunities spent on damage control (Choquenot et al. 1996). Feral swine can harbour a number of diseases transmittable to livestock or humans (e.g. Conger $e t$ al. 1999; Romero \& Meade 1999; Taft 1999). In particular, the swine industry in the USA has nearly eradicated swine brucellosis and pseudorabies, but feral swine serve as a potential reservoir from which these diseases can be transmitted to domestic stock (Taft 1999; Taylor 1999).

One of the greatest current needs for feral swine management is a practical means for indexing their populations (Choquenot et al. 1996). Knowledge of relative swine population abundance and spatial distribution is valuable for delivering oral baits for vaccination, timing control programmes, optimally locating control sites, and evaluating control efficacy.

A variety of methods have been applied for estimating absolute abundance of feral swine, with the methods often requiring many resources and producing mixed results (e.g. Choquenot et al. 1996). This highlights a frequent problem in wildlife biology, namely to accurately and economically assess the population or density of the animal of interest in a logistically practical manner. The statistical theory used to produce density estimates usually requires fulfillment of assumptions, that when violated result in estimates of questionable quality (see for example, Leidloff 2000 for an excellent overview of potential problems with capture-recapture methods and Burnham et al. 1980 for potential hazards with line-transect estimation).

Population density estimates, however, are frequently unnecessary for research or management purposes (e.g. Caughley 1977). Instead, researchers and managers may rely 
on useful indices produced from indirect observation methods. Important among desirable index characteristics, the method should be simple and quickly applied in the field, while providing sensitivity to reflect population changes over time or space (Engeman \& Witmer 2000). Such an index can provide the necessary comparative information to make sound management decisions. In contrast to density estimation, where the premium is on accuracy, precision is of most importance for an index (e.g. Caughley \& Sinclair 1994; Engeman \& Witmer 2000). For the most robust management inferences, the calculated index and associated variance should be burdened with as few assumptions as possible about the data structure and distribution of the observations.

Recently, a passive tracking index (PTI) applied to monitor changes of coyote (Canis latrans) abundance in south Texas was able simultaneously to index feral swine (Engeman \& Allen 2001). This result demonstrated the potential for using the PTI to monitor feral swine in conservation or agricultural damage reduction efforts. Thus, we used the PTI in Jonathan Dickinson State Park (JDSP), Florida, USA, where feral swine are a chronic and acute destructive force to the environment. JDSP is largely a wilderness preserve that is home to unique and dwindling plant communities that are otherwise rapidly being lost to development in Florida. The park holds over 50 plant and animal species listed by the federal or Florida state governments as endangered or threatened, and Florida's only federally designated 'Wild and Scenic River' flows through the park. We applied the PTI to feral swine for evaluating the efficacy of a swine control effort at JDSP. We also used the passive tracking plot data to develop additional feral swine monitoring methods.

\section{Methods}

\section{Study area}

This study was conducted in a $8.3 \mathrm{~km}^{2}$ area of JDSP, which is centrally located along Florida's east coast. Habitat in the study area was a wet pine-flatwoods (Hartman 1978; Kautz 1987) dominated by South Florida slash pine (Pinus elliottii), with saw palmetto (Serenoa repens) as the primary understory species. Tracking plots were established and observed in January 2000, prior to commencement of a swine reduction effort. A contract for swine removal was carried out during April, and other swine were removed opportunistically by park personnel in February and March 2000. Re-using the same tracking plots in May after the control effort allowed us to examine the sensitivity of the PTI for detecting swine population changes. The passive tracking plot assessment using the same plots was carried out again in August to look for evidence of repopulation by feral swine.

\section{Plot set-up}

Tracking plots were placed on the low-use, single-lane dirt (primitive) roads which permeated the study area. We estab- lished 22 plots randomly throughout the study area. We placed plots in sites devoid of vegetative growth in the road to assure us that swine could not visually distinguish the plots from the roadway. The saturation of the study area with primitive roads, coupled with the random occurrences of potential plot sites devoid of vegetation, and our random selection among those sites produced a random spatial pattern of plots in our study area. Only two stakes, located at the edge of roadside vegetation, were used to designate opposite corners of the plots (again, we were minimizing any potential visual impacts from the plots). Flagging tape hung on a tree up-road from the plots presented advance notice to vehicle operators of an upcoming plot so that we would not accidentally drive through them before taking observations. Plots were $1.5 \mathrm{~m}$ long, raked and smoothed to produce a good tracking base that spanned the road-width (approximately 3 $\mathrm{m}$ ). The fine sandy substrate of the area made an excellent tracking surface and no additional substrate was needed to supplement the tracking surfaces. The locations of all plots were recorded using a global positioning system (GPS) unit. At each plot, the number of swine track sets (number of intrusions into the plot) was recorded for two consecutive days at each assessment time. After 24 hours, the plots were examined for spoor and resurfaced (tracks erased and surface smoothed) for the next day's observations. Fair weather conditions prevailed during the three assessments.

\section{Passive tracking index calculations}

The PTIs and associated variances were calculated according to Engeman et al. (1998) where a mixed linear model (e.g. McLean et al. 1991; Wolfinger et al. 1991) was used to describe the number of intrusions on each plot each day. The derivation of the variance formula was based on a non-zero covariance structure among plots and among days, that is, without assumptions of independence among plots or days (Engeman et al. 1998). The mean number of track intrusions on each plot by each species was calculated for each day, and the index values were the means of the daily means:

$$
P T I=\frac{1}{d} \sum_{j=1}^{d} \frac{1}{p_{j}} \sum_{i=1}^{p_{j}} x_{i j}
$$

where the $x_{i j}$ represents the number of intrusions by a given species in the $i^{\text {th }}$ plot on the $j^{\text {th }}$ day, $d$ is the number of days of observation, and $p_{j}$ is the number of plots contributing data on the $j^{\text {th }}$ day. The procedure SAS PROC VARCOMP, with a restricted maximum likelihood estimation procedure (REML) (SAS Institute 1996) was used to calculate the variance components (Searle et al. 1992) needed in the PTI variance estimation formula (Engeman et al. 1998):

$$
\operatorname{var}(P T I)=\frac{\sigma_{p}^{2}}{d} \sum_{j=1}^{d} \frac{1}{p_{j}}+\frac{\sigma_{d}^{2}}{d}+\frac{\sigma_{e}^{2}}{d^{2}} \sum_{j=1}^{d} \frac{1}{p_{j}}
$$

where the $\sigma_{p}^{2}, \sigma_{d}^{2}$, and $\sigma_{e}^{2}$ are, respectively, the components for plot-to-plot variability, daily variability, and random 
observational variability associated with each plot each day. We calculated confidence intervals using the standard normal approximation. We conducted Z-tests to compare pre- and post-swine control population index levels.

\section{Pervasiveness index}

For this study we developed an index to describe the spatial distribution of the feral swine activity. The index, which we call an index of pervasiveness, was modified from Hopkins' (1954) index of aggregation, which has seen other useful modifications (e.g. Engeman \& Sugihara 1998). We defined the index of pervasiveness (IP) as:

$$
I P=(1 / n) \Sigma\left(w_{1} / w_{2}\right)
$$

where $n$ is the number of plots, $m_{1}$ is the square of the distance from a tracking plot to the nearest plot with swine tracks (nearest neighbour sample, Engeman et al. 1994), and $m_{2}$ is the square of the distance from that nearest plot to its nearest plot with tracks (second-nearest neighbour sample, Engeman et al. 1994). Plot locations were mapped, and interplot distances were calculated from the GPS locations using ArcView and Atlas GIS software. When the pattern is entirely random, IP $=1$. If the plots with tracks show aggregation (localized concentrations), then IP $>1$. If tracked plots show a systematic pattern, then IP $<1$. This index could be particularly useful for examining re-invasion patterns by describing the saturation of the area with swine.

\section{Fresh damage index}

As a simplistic (and rough) descriptor of swine damage at each of the monitoring sessions, we used the number of sites of fresh rooting per $\mathrm{km}$ intercepted along our route between plots. Fresh rooting was distinguished from old rooting by examining the moistness of the overturned soil and whether overturned plant roots were dried or fresh. Rooting where the soil had dried and the roots within it had withered was classified as old. Rooting where the overturned soil was still moist on the surface and the roots were alive was classified as fresh. The incidence of fresh rooting along our fixed route between plots formed a secondary indicator of swine activity to complement the PTI.

\section{Results}

Between our January and May monitoring occasions, 25 feral swine were removed from the study area, 22 of those during April as part of the swine control contract. The other three were removed opportunistically by park personnel. The PTI values calculated in January and May reflected the intervening removal of animals, as the PTI value decreased $(Z=$ $3.876, p=0.00011)$ by $81 \%$ from $0.581( \pm 0.233=95 \% \mathrm{CI})$ in January to $0.115( \pm 0.019=95 \%$ CI $)$ in May. Through observations of swine sign along our route between the plots, swine activity in the study area originally appeared concentrated in several areas, but was reduced to only one corner of activity after the control effort. These anecdotal observations were reflected in the increase in value of the index of pervasiveness from 3.1 to 7.3 , indicating that the distribution of swine activity went from a pattern of clumped activity to more isolated activity. Paralleling our other tracking plot data, the rate of observation of fresh damage along our route between plots dropped by $89 \%$ from 1.75 sites $/ \mathrm{km}$ in January to 0.19 sites $/ \mathrm{km}$ in May.

The assessment in August gave no evidence of a population buildup since the control effort, as the PTI further decreased to $0.070( \pm 0.005=95 \%$ CI $)$. The additional decrease in the PTI likely was due to the additional opportunistic removal of three more swine by park personnel. Also reflecting lower populations, no fresh swine rooting was observed along our route between plots in August. The index of pervasiveness for August was 3.6, indicating a spatial pattern of activity more similar to the January assessment than the May assessment.

Tracks from raccoons (Procyon lotor), white-tailed deer (Odocoileus virginianus), armadillos (Dasypus novemcinctus) and canids (Canis spp.) were also observed at least once on our tracking plots. Raccoons were the only species of these for which we felt confident calculating the PTI. Deer and armadillo tracks were found only occasionally on the plots, and coyote (C. latrans) and $\operatorname{dog}(C$. familiaris $)$ tracks could not be distinguished with any degree of confidence. Indexing canids would have been a reflection of tourism, as dogs often accompanied hikers along the dirt roads in the park, while coyotes are just expanding their populations into the area (Cunningham \& Dunford 1970; Brady 1983; Hill et al. 1987; Wooding \& Hardisky 1990). We were not specifically interested in raccoon populations, per se, but their PTI was virtually unchanged $(Z=0.543, p=0.59)$ from January $(0.331 \pm 0.090,95 \% \mathrm{CI})$ to May $(0.385 \pm 0.173,95 \% \mathrm{CI})$, and increased in August $(0.750 \pm 0.20,95 \%$ CI $)$. These results served as an indication that the other wildlife besides swine did not appear to be negatively affected by the swine control, and the changes in index values for swine logically were due to the population reduction effort, rather than some other phenomena that might have been affecting the wildlife in the park.

\section{Discussion}

In Florida, a premium is placed on sanctuaries for protection and preservation of habitats and species, especially as much of the natural habitat in Florida has been lost to development. JDSP, where our study took place, is home to a variety of threatened and endangered plant and animal species, as well as unique habitats. Swine are controlled to alleviate their negative impacts on these resources. Choquenot et al. (1996) state that a major deficiency of current feral swine management is the lack of a simple, readily applied system for measuring abundance. We demonstrated indices for moni- 
toring abundance, distribution, and damage of feral swine, which promote more effective and economical management of their impact (Choquenot et al. 1996).

Due to the logistical and theoretical difficulties associated with density estimation methods, Choquenot et al. (1996) advised that indices of abundance, rather than absolute abundance estimates, were the only practical means for monitoring swine. Their suggestions for monitoring methods included observations of sign (wallows, rooting, tracks, and droppings), mark-recapture, catch-per-unit-effort, and bait-take. To be other than anecdotal, observation of wallows, rootings, and droppings require a sampling plan, and still present difficulties for determining the time frame of occurrence.

Mark-recapture becomes a labour-intensive population indexing effort when the assumptions for density estimation cannot be fulfilled. For our purposes at JDSP, imagine the impracticality of employing mark-recapture before and after a control programme to evaluate efficacy. There could be little validity in assuming that repeated captures before and after, plus the effects of the intervening control, would not result in heterogeneity of recapture rates. In addition, our results indicate it unlikely than many more than the 25 swine removed would initially have been available for a mark-recapture study. After control there would have been many fewer. Thus, insufficient information would have been available for producing appropriately descriptive mark-recapture models. However, the PTI provided valid statistical data on an indirect measure of swine populations.

Catch-per-unit-effort is likely to be part of a control campaign, and, as with bait-take observations, is likely to introduce bias into the assessment by conditioning the animals being observed. This is especially true when considering the learning capabilities of pigs, as exemplified by feral pigs acting dead during aerial surveys of helicopter-shot pigs (Saunders \& Bryant 1988). In another context, bait-take measurements have also been shown to be less sensitive to presence and more prone to bias due to differential responses than passive tracking plots (Allen et al. 1996). The most accurate population assessment solution might be a passive mark-recapture system. Such an approach would require an investment in sophisticated equipment to detect animals without affecting behaviour, and it would be labour-intensive to distinguish among recorded individuals to identify recaptures. At the present, such methodology is used for some research applications (M. Jaeger, personal communication 2000), but is not practical for general management applications.

The habitat in our study area was dominated by dense stands of saw palmetto with moist sandy to wet swampy substrate. While cover is a well-known habitat requirement for feral swine (e.g. Sweeney \& Sweeney 1982; Choquenot $e t$ al. 1996; Demarais \& Krausman 2000), particularly river bottoms and swampy areas in the southern USA (Kurz \& Marchinton 1972), the nature of the off-road habitat in JDSP undoubtedly predisposes swine to year-round preferential use of the road network for their travel-routes. Therefore, plot placement on the roads for indexing purposes reflects population abundance and distribution, because of (rather than despite) preferential usage of roads as routes.

We found no track evidence that feral swine either avoided or were attracted to the tracking plots. No trail of tracks deviated from its route toward or away from the plots. Tracks on the plots appeared strictly as intersections with the natural travel patterns of the swine. A method based on counting daily movements of animals across passive (no attractants) tracking stations would be unlikely to influence normal animal activity, and we went to lengths to ensure that plots were not distinguishable from the road section in which they were placed. As with any other aspect of sampling, potential confounding effects must be identified and avoided. Thus, comparative inferences from index values taken from markedly different environments could be confounded with potential differences in road usage by feral swine in different habitats.

Various factors can affect observations on tracking plots other than population density. However, Bider (1968), in a comprehensive study using 182000 observations in sand transects, concluded population density was the most important factor affecting activity on tracking plots. Territory size and proportion of territorial animals may differ substantially from habitat to habitat, and after changes in population density. This, too, affects accuracy when attempting to relate an index value to population density. However, statistically detectable changes or differences in index values permit inferences and management decisions when applied to comparable circumstances.

The PTI relies on the detection and correct identification of spoor left on the plots and the ability to distinguish the number of individual intrusions within a plot. Spoor might be missed if the tracking plot is inadequately prepared or if the observers are not trained. Rain, wind and traffic might further obscure or obliterate tracks. Although we found no problems with superimposed tracks when more than one animal crossed the plots, this could pose a problem for monitoring large groups in some situations. Loss of information from tracking plots cannot be prevented entirely, but it can be minimized with careful attention to plot preparation. The loss of some data do not seriously affect calculations of the PTI and its variance, as activity is averaged over many plots and over multiple days.

The variance components calculated for use in the PTI variance formula also provide helpful planning information (e.g. Searle et al. 1992), as the relative contributions of plotto-plot variation and day-to-day variation can be examined to optimize the combination of days and plots. The component of variance for plot-to-plot variation was orders of magnitude larger than the other sources of variation for each monitoring session. Thus, if the outlook is for consistent good weather during data collection, then the emphasis should be placed on the number of plots. However, if the weather could change during the assessment period, then the number of observation days should be increased, or the assessment delayed. Nonetheless, the reality of wildlife surveys often is that logis- 
tics and resources are the most important influences on sampling design. Because of the data structure for the PTI, the index, variance and associated statistics still will be calculable, but the variability will reflect the changing circumstances and will be higher, thus decreasing sensitivity for detecting differences or changes.

The inter-plot distances of closest and next-closest plots with tracks provides data to calculate a useful descriptive index indicative of the activity patterns within an area. This information on activity patterns could be of conceptual benefit when formulating damage control strategies, including population reduction. Because lower IP magnitudes indicate greater saturation of swine activity in an area, taking the IP in conjunction with the PTI for indexing abundance provides a useful indicator of repopulation. The index of fresh damage along the roads is descriptive and complementary to the tracking plot information for assessing quantity and patterns in swine activity, but it should not be considered as a primary abundance index because it relies on somewhat subjective assessment of 'fresh' damage, and it is susceptible to biases through time if swine shift their food (rooting) habits as seasons change.

The use of the permanent passive tracking plot locations provided a useful means to assess the changes in feral swine abundance, while simultaneously providing information to describe the spatial distribution of their activity. As a result of this monitoring effort, the same tracking plots will be incorporated as a practical means to further monitor for repopulation of the area by feral swine on a quarterly basis, and to assess the necessity and efficacy of future control.

\section{Acknowledgements}

K. Fagerstone, M. Fall, R. Sterner, K. VerCauteren and G. Witmer provided insightful reviews of earlier drafts of this manuscript.

\section{References}

Allen, L., Engeman, R.M. \& Krupa, H.W. (1996) Evaluation of three relative abundance indices for assessing dingo populations. Wildlife Research 23: 197-206.

Bider, J.R. (1968) Animal activity in uncontrolled terrestrial communities as determined by a sand transect technique. Ecological Monographs 38: 269-308.

Brady, J.R. (1983) Distribution of coyotes in Florida. Florida Field Naturalist 11: 40-41.

Burnham, K.P., Anderson, D.R. \& Laake, J.L. (1980) Estimation of density from line transect sampling of biological populations. Wildlife Monographs 72: $202 \mathrm{pp}$.

Caughley, G. (1977) Analysis of Vertebrate Populations. New York, USA: Wiley \& Sons: 254 pp.

Caughley, G. \& Sinclair, A. (1994) Wildlife Ecology and Management. Cambridge, MA, USA: Blackwell Science: 334 pp.

Choquenot, D., McIlroy, J. \& Korn, T. (1996) Managing Vertebrate Pests: Feral Pigs. Canberra, ACT, Australia: Bureau of Resource Sciences, Australian Government Publishing Service: 163 pp.

Conger, T.H., Young, E. \& Heckmann, R.A. (1999) Brucella suis in feral swine. In: Proceedings of the 1999 National Feral Smine Symposium, pp. 98-107. Austin, TX, USA: Texas Animal Health Commission.

Cunningham, V.D. \& Dunford, R.D. (1970) Recent coyote record from Florida. Quarterly Fournal of the Florida Academy of Sciences 33: 279-280.

Demarais, S. \& Krausman, P.R. (2000) Ecology and Management of Large Mammals in North America. Upper Saddle River, NJ, USA: Prentice Hall: 778 pp.

Engeman, R.M. \& Allen, L. (2001) Overview of a passive tracking index for monitoring wild canids and associated species. Integrated Pest Management Reviems, in press.

Engeman, R.M., Allen, L. \& Zerbe, G.O. (1998) Variance estimate for the Allen activity index. Wildlife Research 25: 643-648.

Engeman, R.M. \& Sugihara, R.T. (1998) Optimization of variable area transect sampling using Monte Carlo simulation. Ecology 79: $1425-1434$.

Engeman, R.M., Sugihara, R.T., Pank, L.F. \& Dusenberry, W.E. (1994) A comparison of plotless density estimators using Monte Carlo simulation. Ecology 75: 1769-1779.

Engeman, R.M. \& Witmer, G.W. (2000) IPM strategies: indexing difficult to monitor populations of pest species. Vertebrate Pest Conference 19: 183-189.

Gipson, P.S., Hlavachick, B., Berger, T. \& Lee, C.D. (1997) Explanations for recent range expansions by wild hogs into midwestern states. Great Plains Wildlife Damage Control Workshop 13: $148-150$.

Hartman, B.J. (1978) Description of major terrestrial and wetland habitats of Florida. In: Rare and Endangered Biota of Florida. Volume 2: Birds, ed. H.W. Kale, pp. xvi-xix. Gainesville, FL, USA: University Presses of Florida.

Hellgren, E. (1999) Reproduction in feral swine. In: Proceedings of the 1999 National Feral Swine Symposium, pp. 67-68. Austin, TX, USA: Texas Animal Health Commission.

Hill, E.P., Sumner, P.W. \& Wooding, J.B. (1987) Human influences on range expansion of coyotes in the southeast. Wildlife Society Bulletin 15: 521-524.

Hopkins, B., with appendix by Skellum, J.G. (1954) A new method for determining the type of distribution of plant individuals. Annals of Botany. Nem Series 18: 213-227.

Kautz, R. (1987) Preliminary cover types for Landsat inventory. Tallahassee, FL, USA: Florida Game and Freshwater Fish Commission, Office of Environmental Services, Nongame Wildlife Section.

Kurz, J.C. \& Marchinton, R.L. (1972) Radiotelemetry studies of feral hogs in South Carolina. Fournal of Wildlife Management. 36: $1240-1248$.

Leidloff, A.C. (2000) Habitat utilisation by the grassland Melomys (Melomys burtoni) and the swamp rat (Rattus lutrelus) in a coastal heathland of Bribie Island, South-East Queensland. Ph.D. Dissertation, Queensland University of Technology, Australia: $135 \mathrm{pp}$.

McLean, R.A., Sanders, W.L. \& Stroup, W.W. (1991) A unified approach to mixed linear models. The American Statistician 45: 54-64.

Romero, C.H. \& Meade, P.N. (1999) Pseudorabies virus in feral swine: a research update. In: Proceedings of the 1999 National Feral Smine Symposium, pp. 73-74. Austin, TX, USA: Texas Animal Health Commission.

SAS Institute (1996) SAS/STAT User's Guide. Carey, NC, USA: SAS Institute: $1686 \mathrm{pp}$. 
Saunders, G. \& Bryant, H. (1988) The evaluation of a feral pig eradication program during a simulated exotic disease outbreak. Australian Wildlife Research 15: 73-81.

Searle, S.R., Casella, G. \& McCulloch, C.E. (1992) Variance Components. New York, NY, USA: Wiley \& Sons: 501 pp.

Sweeney, J.M. \& Sweeney, J.R. (1982) Feral Hog. In: Wild Mammals of North America, eds. J.A. Chapman \& G.A. Feldhamer, pp. 1099-1113. Baltimore, MD, USA: Johns Hopkins University Press.

Taft, A.C. (1999) Feral swine - national concerns. In: Proceedings of the 1999 National Feral Swine Symposium, pp. 25-26. Austin, TX, USA: Texas Animal Health Commission.

Taylor, R.B. (1999) Seasonal diets and food habits of feral swine. In: Proceedings of the 1999 National Feral Swine Symposium, pp. 58-66. Austin, TX, USA: Texas Animal Health Commission.
Towne, C.W. \& Wentworth, E.N. (1950) Pigs from Cave to Cornbelt. Norman, OK, USA: University of Oklahoma Press: 305 pp.

US Department of Agriculture (1999) Wild pigs hidden danger for farmers and hunters. Animal and Plant Health Inspection Services Information Bulletin 620. Washington, DC, USA: 7 pp. Wolfinger, R.D., Tobias, R. \& Sall, J. (1991) Mixed models: a future direction. In: 16th SAS Users Group Conference, ed. M. Rosenburg, pp. 1380-1388. Carey, NC, USA: SAS Institute.

Wooding, J.B. \& Hardinsky, S. (1990) Coyote distribution in Florida. Florida Field Naturalist 18: 12-14.

Wood, G.W. \& Barrett, R.H. (1979) Status of wild pigs in the United States. Wildlife Society Bulletin 7: 237246 . 